\title{
Integrando Agropecuária, Física e Informática para o bem-estar animal: conforto térmico para suínos
}

\author{
Michel Luís Rohr ${ }^{1}$, Jefferson de Oliveira Chaves ${ }^{1}$, Leandro Marcos Salgado Alves ${ }^{1}$ \\ ${ }^{1}$ Instituto Federal Catarinense (IFC), Campus Araquari \\ Caixa Postal 21 - 89.245-000 - Santa Catarina - SC - Brazil \\ \{michelrohr8@gmail.com, jefferson.chaveseifc.edu.br, \\ leandro.alveseifc.edu.br\}
}

\begin{abstract}
Piglets needs of very careful in the first weeks of your life. Until the fourth week the contraction of illnesses is quite common in cold environments. In this work we present the development of a prototype of creep with digital controlled sensor to monitor the temperature. The creep is composed of ducts that conduct hot water under the floor. Sensors monitor the temperature and allow adjustments that improve the thermal comfort of the piglets and increase the economy and production quality.

Resumo. Os leitões necessitam de muito cuidado nas primeiras semanas de vida. Até a quarta semana a contração de enfermidades é bastante comum em ambientes frios. Neste trabalho apresentamos o desenvolvimento de um protótipo de escamoteador controlado por sensores digitais que monitoram a temperatura. O escamoteador é composto de dutos que conduzem água quente por baixo do piso. Sensores monitoram a temperatura e permitem ajustes que melhoram o conforto térmico dos leitões e aumentam a economia e a qualidade da produção.
\end{abstract}

\section{Introdução}

Diferentes fatores são determinantes na obtenção de carne suína de qualidade. Podemos classificá-los em intrínsecos e extrínsecos. Os genéticos são exemplos de intrínsecos e o manejo de extrínsecos (Freitas, 1996; Roppa, 2001). Referente ao manejo, o produtor deve procurar mecanismos que favoreçam o bem-estar animal para aumentar a eficiência do mesmo em transformar alimento em peso vivo (Freitas, 1996; Roppa, 2001). Nas primeiras semanas de vida os cuidados devem ser aumentados, pois os leitões nascem com os sistemas termoregulador e imunológico pouco desenvolvidos, exigindo cuidados especiais (Freitas, 1996; Roppa, 2001). A preocupação com o conforto térmico é muito relevante. A temperatura ideal para os suínos é de aproximadamente $32^{\circ} \mathrm{C}$ (Freitas, 1996; Moraes et al., 1991; Roppa, 2001). Por isso, o ambiente de maternidade deve ser mantido próximo dessa temperatura (Sobestiansky et al., 1998). Caso isso não ocorra, os leitões podem ser acometidos de doenças respiratórias, diarreias, hipotermia, perda de peso, e em casos extremos, vir a óbito (Moraes et al., 1991; Moraes, 1993; Sobestiansky et al., 1998).

Com base no exposto, este projeto, que é a continuação de um trabalho anterior, tem por objetivo desenvolver um ambiente favorável para que os leitões ganhem peso e, ao mesmo tempo, tenham reduzida as chances de adquirir doenças infecciosas zelando por economia na operação do sistema térmico (Rohr et al., 2017). 


\section{Metodologia}

Produziu-se um protótipo de piso térmico para simular condições desejadas para a maternidade dos leitões. A figura 1 apresenta fotografias das etapas iniciais do projeto.

a)

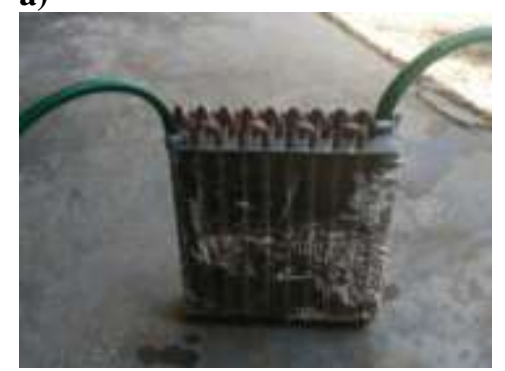

b)

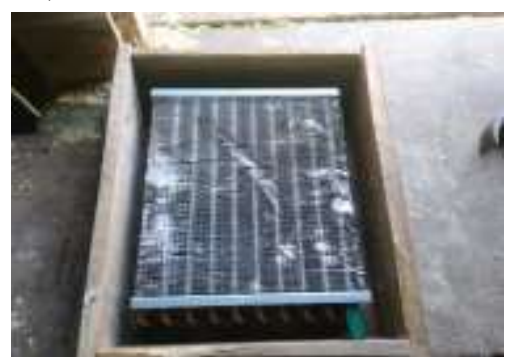

c)

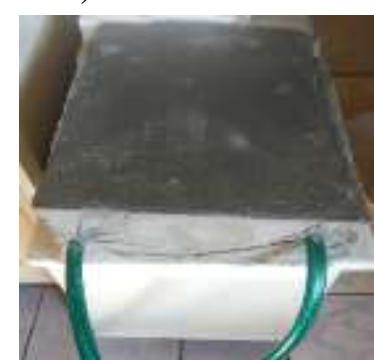

Figura 1. a) sistema de serpentinas para a circulação de água quente; b) serpentinas num molde de madeira para preenchimento com argamassa; c) molde preenchido com argamassa e mangueiras para conexão com as fontes de água quente e fria (Fonte: Rohr et al., 2017).

$\mathrm{Na}$ montagem do piso térmico foi aproveitado um radiador de carro, como mostrado na figura 1a e 1b. Duas mangueiras foram conectadas entre as fontes de água quente e fria, permitindo a circulação pela serpentina. Na figura 1c é mostrado o sistema já preenchido com argamassa. Foram utilizados aproximadamente $10 \mathrm{~kg}$ de argamassa. $\mathrm{O}$ protótipo final apresentou dimensões de $35,5 \mathrm{~cm} x 30,0 \mathrm{~cm} \times 9,5 \mathrm{~cm}$. A figura 2 mostra uma foto do protótipo terminado e em fase de testes.

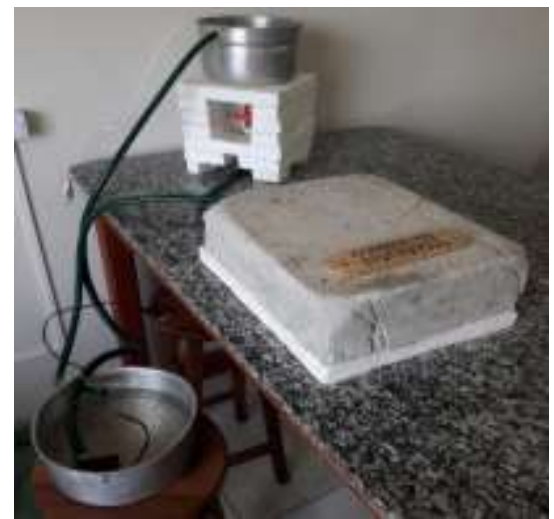

Figura 2. Fotografia do protótipo de piso térmico para suínos (Fonte: Rohr et al., 2017).

Para o aquecimento da água foi utilizado um resistor semelhante ao do chuveiro. A fonte de água quente foi posicionada na parte superior e a fonte de água fria na parte inferior. Por gravidade, a água quente desce para a fonte fria. Utilizando-se uma bomba de aquário, a água da fonte fria é novamente bombeada para o reservatório superior, onde é novamente aquecida.

$\mathrm{Na}$ fase inicial do projeto a temperatura foi medida manualmente, impossibilitando o monitoramento contínuo e a obtenção mais eficiente de dados. Assim, pretende-se utilizar sensores de temperatura digitais para aperfeiçoar a aquisição de dados e melhorar a capacidade de tomadas de decisões para projetos futuros.

Nesse sentido, os dados de temperatura serão obtidos por meio de sensores DS18B20. Esse tipo de sensor tem como características a medição de temperaturas entre $-55^{\circ} \mathrm{C}$ e $+125^{\circ} \mathrm{C}$, precisão ajustável entre 9 e 12 bits. São a prova de água, umidade e ferrugem, além de utilizar o protocolo 1-Wire para leitura de múltiplos sensores (Maxim 
Integrated Products, 2015). Nesse trabalho serão utilizados um conjunto de sensores. Cada sensor possui uma identificação chamada de serial number tornando possível identificar individualmente cada sensor conectado ao barramento, de forma a possibilitar a identificação de sensores que apresentem dados discrepantes. Os dados obtidos dos sensores serão enviados para uma placa Arduino que, por sua vez os enviará, dado um parâmetro de tempo, para um software responsável por receber, normalizar, armazenar e tabular os dados. O software deve permitir a visualização de tais dados de forma gráfica.

Para um projeto de proporções reais a bomba que elevará a água até a fonte quente poderá ser elétrica ou um carneiro hidráulico (Silveira et al., 2015). Sendo que essa última opção diminuirá os custos para o produtor. A energia para o aquecimento da água poderá ser obtida através da queima do biogás produzido por um biodigestor (Ferreira et al., 2011,), por energia elétrica (Rosi, Cardoso, Beraldo, 2002) ou pela queima de lenha. Esta água poderá ser reutilizada para irrigação, por exemplo.

\section{Resultados}

Antes da aquisição dos sensores foram feitas algumas medidas de forma manual. A temperatura do piso térmico foi monitorada em duas situações diferentes. Num primeiro momento aqueceu-se a água que circula pelos dutos do piso até $42^{\circ} \mathrm{C} \mathrm{e}$, em seguida, desligou-se o aquecedor resistivo. Logo após, mediu-se a temperatura da superfície do piso em função do tempo por aproximadamente uma hora e meia. A taxa de variação da temperatura do piso é mostrada na figura $3 \mathrm{a}$. Num segundo momento, aqueceu-se a água até $48^{\circ} \mathrm{C}$ e repetiu-se o processo. O resultado é mostrado na figura $3 \mathrm{~b}$.
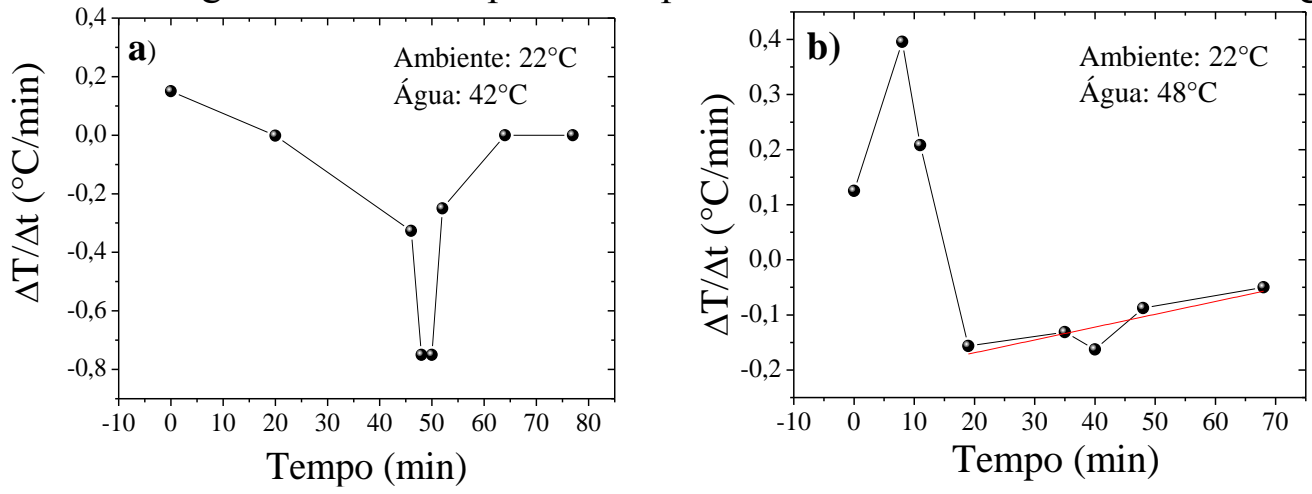

Figura 3. a) Taxa de variação da temperatura do piso térmico em função do tempo após desligar $o$ aquecedor resistivo no momento em que a água da fonte quente atinge $42^{\circ} \mathrm{C} \mathrm{e} \mathrm{b}$ ) após atingir $48^{\circ} \mathrm{C}$.

$\mathrm{Na}$ primeira situação, quando a água atinge $42^{\circ} \mathrm{C}$, a temperatura inicial do piso é de $36^{\circ} \mathrm{C}$. Nos primeiros 45 minutos a temperatura do piso diminuiu, fornecendo calor para a água que circula pelos dutos. Após 50 minutos de operação a temperatura do piso voltou a subir, absorvendo calor da água da tubulação. Depois de 1 hora a temperatura do piso estabiliza-se em $31{ }^{\circ} \mathrm{C}$ e a taxa de variação de temperatura do piso vai para zero. Nesse momento o piso e a água entram em equilíbrio térmico. Na figura $3 \mathrm{~b}$ a água é aquecida até $48^{\circ} \mathrm{C}$. A temperatura inicial do piso é de $35^{\circ} \mathrm{C}$. Nos primeiros 10 minutos a temperatura do piso aumenta, recebendo calor da água. Nos próximos 10 minutos o piso cede calor para a água. Em seguida a temperatura do piso tende para o equilíbrio térmico, que deve acontecer após 1 hora e 33 minutos de operação. Valor estipulado pelo ajuste linear da reta no intervalo de 20 a 70 minutos. 


\section{Conclusões}

Neste trabalho foi construído um protótipo de piso térmico utilizando um sistema de fluxo de água aquecida. Os resultados dos ensaios mostraram que quando a água atinge temperaturas de $42^{\circ} \mathrm{C}$ e $48^{\circ} \mathrm{C}$ é possível manter o piso aquecido entre $30^{\circ} \mathrm{C} \mathrm{e}$ $40^{\circ} \mathrm{C}$ por mais de uma hora, sem a necessidade de manter o aquecedor ligado. Diante dos resultados prévios os autores acreditam que o monitoramento de temperatura realizado por sensores de forma sistematizada permitirá a determinação da capacidade térmica do piso e nos dará parâmetros para avaliar a utilização de outros materiais de diferentes propriedades térmicas. Entendemos que é possível, monitorando a temperatura da água, determinar, para diferentes temperaturas da água corrente pelos dutos, a temperatura máxima que o piso atingirá e em qual temperatura ele se estabilizará, e por quanto tempo a temperatura de equilíbrio será mantida.

A utilização de sensores digitais que se comunicam com o a placa Arduino e se comunica com o software para obtenção dos dados está em fase de desenvolvimento. Testes começaram a ser realizados e os resultados serão mostrados na apresentação presencial do trabalho. Pretende-se obter melhorias no sistema que proporcionarão conforto térmico para os leitões, garantindo aumento de qualidade e economia para o produtor.

\section{Referências}

Ferreira, C. M. et al. Biodigestor para o gás do lixo orgânico. Exacta, Belo Horizonte, EditoraUniBH. V. 4, n. 2 - Edição Especial Interdisciplinaridade. P.5-17, 2011.

Freitas, H.T. Manejo para desmame de leitões aos 21 dias de idade. 1996. 43f. Dissertação (Mestrado em Zootecnia) - Universidade Federal de Viçosa, Viçosa. 1996.

Rohr, M. L. et al. Piso térmico para Suínos. X Mostra Nacional de Iniciação Científica e Tecnológica Interdisciplinar (MICTI), 2017.

Maxim Integrated Products. DS18B20 - Programmable Resolution 1-Wire Digital Thermometer. $2015 . \quad$ Disponível em: $<$ https://datasheets.maximintegrated.com/en/ds/DS18B20.pdf $>$. Acesso em: 23 de Abr. de 2018.

Moraes, N. Fatores que limitam a produção de leitões na maternidade. Concórdia, v. 2, n. 9, p. $1-5,1993$.

Moraes, N. et al. Fatores de risco associados à diarréia, mortalidade e ao baixo desempenho dos leitões. Concórdia, v. 178, p. 1 - 5, 1991.

Roppa L. Os principais fatores que afetam o Desempenho dos suínos de engorda. Pork World, 1: 24-27, 2001.

Rossi, L. A.; Cardoso, P. E. R.; Beraldo, A. L. Desempenho de placas de argamassa de cimento e casca de arroz aquecidas por resistência elétrica. In: Congresso Brasileiro de Engenharia Agrícola, 31., Salvador, 2002. Anais. Salvador: SBEA, p. 249-252, 2002.

Silveira, L. A. et al. Construção e rendimento de carneiro hidraulico de pvc. In: IV Congresso Estadual de Iniciação Científica do IF goiano, 2015.

Sobestiansky, J. Wentz, I. Silveira, PRS. Sesti LAC. Suinocultura intensiva: produção, manejo e saúde do rebanho. Concórdia, EMBRAPA - CNPSA. 388p, 1998. 